\title{
Teaching Experience Design using poems as cultural probes
}

\author{
Patrizia Marti ${ }^{1}{ }^{2}$ Fabienne van Leiden ${ }^{2}$ \\ ${ }^{1}$ University of Siena, Siena 53100, Italy \\ ${ }^{2}$ Eindhoven University of Technology, Eindhoven, \\ marti@unisi.it
}

\begin{abstract}
Training User Experience (UX) Design students to develop interactive products valuing the subjective experience as a catalyst is a challenge. Experience design implies a deep understanding of the values, culture, beliefs and practices of a target user group and also sensitivity to consciously integrate them in products with distinctive qualities. This paper presents a method experimented along three years of the Master's Degree Program in Industrial Design at Eindhoven University of Technology. The method uses poems as cultural probes and as an access door to experience cultural elements and to embed them in the design of meaningful interactions. Beside the presentation of the method, the paper illustrates student projects that exemplify the approach. It concludes with recommendations to experience designers for transforming socio-cultural factors into product features which promote a valuable subjective experience.
\end{abstract}

Keywords: User Experience Design, Subjective experience, Poetic Design, Cultural Probes.

\section{Introduction}

UX is a field of study in human-computer interaction that focuses on the human subjective experience in interaction with technological artefacts. While this field of study has reached an increasing popularity and maturity, there is still not consensus on how the concept of UX should be defined, researched and taught.

Various scholars have proposed different definitions for UX. Law and colleagues [1], surveyed 110 researchers and on the basis of their survey, published the User Experience White Paper [2] that was included in the revised ISO standard for humancentered design (ISO 9241-210) in 2010. These documents share two main aspects affecting UX that go beyond the characteristics of the product or service like appearance, functions, and performance: 1) a focus on the values that people recognize in a product or service over time [3]; 2) a focus on the subjective experience tied to personal attitudes, expectations and feelings.

Glanznig [4] identifies two major competing strands of research in UX both centred on the study of the subjective experience in interaction with technological artefacts. The first one aims at uncovering the objective in the subjective [5] and is more oriented to identify means to evaluate the UX, the second one takes ambiguity as a distinctive 
quality of experience which is situated and creative [6]. The first approach is grounded in psychology, the second one takes an interpretative and qualitative approach toward UX.

Other notable tendencies in the field are that of designing for emotions and affection $[7,8]$ and for pleasurable and attractive experiences of use.

Assuming a positive attitude of the users to be pleased by using interactive technologies and have fun, Overbeeke et al. [9] stated "Interfaces should be surprising, seductive, smart, rewarding, tempting, even moody, and thereby exhilarating to use. The experiential is assumed to lead to joy of use." (ibid, p.2).

Other researchers used similar features of surprise and imagination to provoke people to critically reflect upon the use of an artefact [10] and make sense of complex, contradictory and even ambiguous systems and situations [11].

These perspectives and approaches to Experience Design raise two main reflections: first of all, designing for experience beyond usability is not a question anymore, but a broadly accepted and explored area within design, with a shift from functionality to experience design.

Secondly, the challenges that technology poses on our contemporary society are of increasing complexity, and this calls for new ways of interacting with digital materials that include "subtle poetic elements to excite imagination" [12] (ibid p.269) and stimulate reflection and sense-making.

\section{Poems as cultural probes}

The research described in this paper looks at experience design acknowledging the complexity of human needs and desires when engaging with interactive systems.

We take "poetic interaction" literally, using poems as cultural probes and sensitizing tool for interactive system design. In this way we hope to stimulate design students and educators to promote design solutions focusing on subjective reflection and sense-making.

Cultural probes have become a popular method in design research to gather qualitative data based on user self-documentation. This method was first introduced by Gaver et al. [13] to encourage users to look beyond functional needs, into the fuzzier realm of their beliefs, desires and cultural preferences. Cultural Probes are a collection of tools, typically maps, a camera, a diary, that participants are invited to use to record meaningful accounts of their daily lives. The collected probes are in turn interpreted by the design team in their raw form as inspiration for their work and a means to reflect on the culture of participants.

From the original formulation, the concept of cultural probes has been variously adapted. Crabtree et al. [14] developed Technology Probes to inspire design by exposing users to new experiences by situating existing technologies in their homes. Peeters et al. [15] used smart sensor agents as Experiencial Probes to gather data on users' behaviour unobtrusively. Other adaptations of Cultural Probes include Experience Probes [16] and Empathy Probes [17] used to move from design inspiration to acquiring information about users and design empathy. 
Mainly probes are applied in design to inspire the design team, to inform design with data, to establish a dialogue with users, or as a means for participation [18]. In all cases they can be regarded as a research vehicle to learn about people's life, culture, needs, choices, behavior, thoughts, values with various techniques: in real time together with people; or longitudinally and remotely.

In what follows we describe our adaptation of cultural probes which use poems as a vehicle to sensitize the designer to the subtleties of a local culture. Our poetic probes are not designed tools to collect data. They can be generated by the participants or selected from existing ones in various ways (books, digital libraries, online communities). The poetic probes can be regarded as very peculiar representations of users' experiences, feelings, attitudes and values, which are narrated with a rich, sometimes ambiguous language purposefully used to reflect, provoke, disclose and offer a viewpoint, a sentiment or emotion.

In the paper, our probing method is exemplified by actual design cases developed within the course "Poetry in design" of the Master's Degree Program in Industrial Design at Eindhoven University of Technology, where poems were used for uncovering underlying or implicit cultural differences and similarities as well as for general sensitization towards subjective experience and sense-making of young designers.

The assignment of the course was to redesign a mundane object that reflected the qualities of a selected poem. Whatever culture the poem came from, it was explored taking also the viewpoint of a different culture by translating the poem in different languages and trying to make sense of cultural meaning and context. The student design teams were purposely multicultural to stimulate a debate on the interpretation of the poetic probes.

The students experimented with an incremental design process developing from abstract analysis to concrete experienciable designs [19].

In what follows first we describe two exemplar students' projects and later we illustrate the design process discussing the individual steps and their implications for UX Design.

\section{Students' projects}

\subsection{Teh Lampu}

Teh Lampu is a redesign of the tea drinking experience which combines some practices of drinking tea of Eastern and Western world.

The product Teh Lampu consists out of a matt tea glass and a stirring stick with a top that lights up when it comes in contact with water (Figure 1). The combination of the matt glass, loose tea leaves - which are common in Indonesian tea rituals - and the light, create dynamic shadow plays on the glass. The stirring stick with the light creates an even more dynamic shadow play when fulfilling its function. If the stirring stick is not used, the tea leaves cause a calmer shadow play, because the leaves are slowly sinking to the bottom, indicating the tea is ready to drink. 


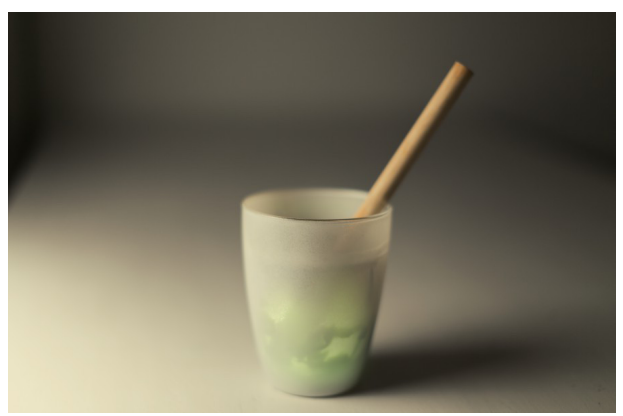

Fig. 1. Teh Lampu

Drinking tea is a rather mundane activity, and often a social one. But when you are drinking, you close yourself off from the conversation, both in communication and in covering yourself with the glass. The light effect on the glass however maintains the communication by giving others a beautiful shadow play. The aim of this design is to bring imagination, which in a sense is almost at par with reality in the Indonesian culture, to the Western culture in this more mundane activity. A video describing the design process and the final product is available at: https://www.youtube.com/watch?v=E6MYr7Hg4RI\&feature=youtu.be

The design is based on the Indonesian poem Teh Lampu by Sapardi Djoko Damono (1974), and inspired on the Asian tea culture (Poem 1). An English translation of the poem follows (Poem 2). In section 4 below, we illustrate how the poem was used to probe the design of Teh Lampu.

\section{Bola Lampu}

Sebuah bola lampu menyala tergantung dalam $\mathrm{ka}$ mar. Lelaki

itu menyusun jari-jarinya dan bayang-bayangnya tampak bergerak di dinding; "Itu kijang," katanya. "Hore!" teriak anak-anaknya, "sekarang harimau!" "Itu harimau." Hore! "Itu gajah, itu babi hutan, itu kera..."

Sebuah bola lampu ingin memejamkan dirinya. Ia merasa

berada di tengah hutan. Ia bising mendengar hingarbingar kawanan binatang buas itu. Ia tiba-tiba merasa asing dan tak diperhatikan.

Poem 1. "Bola Lampu" (C) 1973, Sapardi Djoko Damono Publisher: Puisi Indonesia, Jakarta, 1974.

\section{Light bulb}

A light bulb hangs shining in the room. The man entwines his fingers and their shadows seem to

move on the wall; "A deer," he says. "Hooray!"

shout his children. "Now a tiger!"

"A tiger.” Hooray! "An elephant, a wild boar, a monkey..."

A light bulb wants to close itself off. He feels to be

in the middle of a jungle. He hears loud noises clamour of the group of wild beasts. Suddenly he feels estranged and unnoticed.

Poem 2. Translation from "Bola Lampu" by Separdi Djoko Damono (1974). (C) 2015: G. de Boer, T. Elfferich, F. van Leiden, J. Vlaming 


\subsection{Deer Enclosure}

Deer Enclosure is a redesign of an answering machine that keeps messages hidden until they are revealed by the listener (Figure 2).

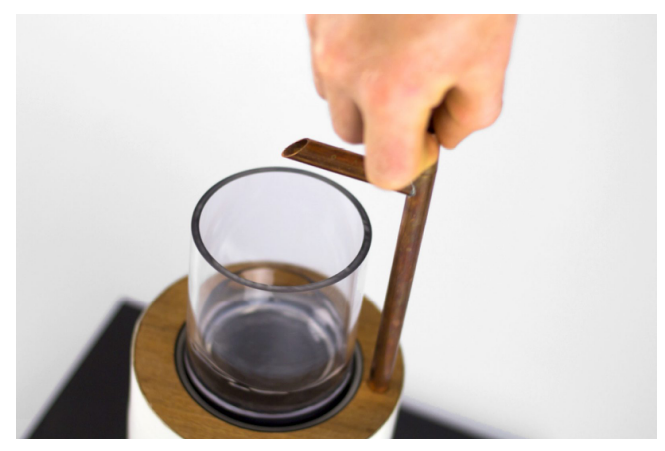

Fig. 2. Deer Enclosure

Incoming messages are abstractly represented by water that pours from the tap into the main cup. Messages are constantly played back, but due to the water they are muffled away, like "echoing voices" (Poem 4).

The messages are only revealed when the receiver spins the water forming a vortex which allows the message to come out of the speakers. Since this vortex requires a specific speed, this activity requires a state of seclusion and focus. Now and then, the cup has to be emptied to make space for new messages by pouring the water out in the sink, again revealing the speakers and with this the old messages.

A video describing the final concept is available at: https://vimeo.com/194223510. The process video can be accessed through this link: https://vimeo.com/194223457.

The design integrates inspirational elements from the ancient Chinese poem "Deer Enclosure" (Chinese translation of Lù Zhai) by Wang Wei (Poem 3), inspired by the meditation rituals in Asian cultures. The way the poem was used to probe the design process is illustrated in section 4 .

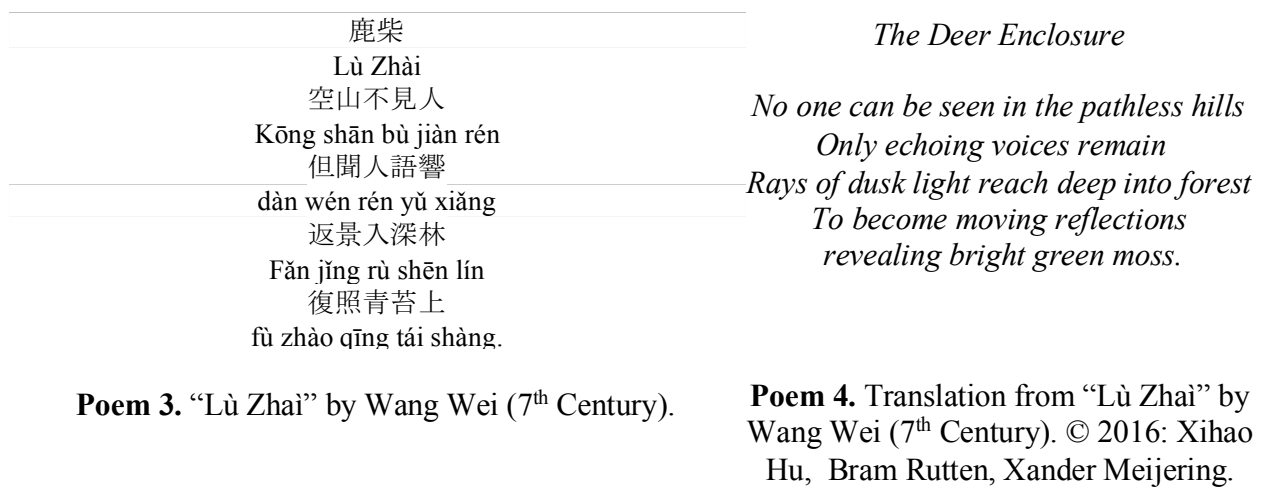




\section{$4 \quad$ Design process}

In the following we present the process underlying the development of the projects described above, and the way in which poems were used as inspirational cultural probes. We first describe the overall picture (Figure 3), and later we detail the different methodological steps exemplified by the material extracted by projects.

The design process was incremental and developed through cycles from abstract to concrete. The waving line in Figure 3 shows the constant switch between abstract reflection and concrete explorations.

The whole process is entirely driven by a deep appreciation of the qualities of a selected poem. This process develops with incremental steps starting with making a bodily experience of the poem by reading, reciting and listening (concrete step) through a deep analysis of contents, language and meaning (abstract step). In this way, the deeper layers of the poems are explored, qualities extracted and translated into design properties and a final prototype.

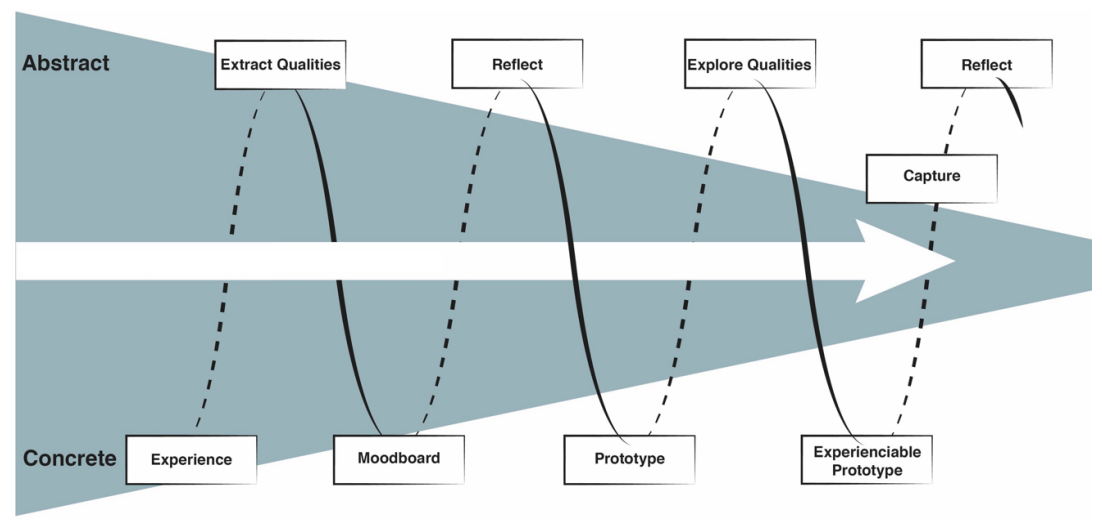

Fig. 3. Overall picture of design process. The waving line indicates the constant switch between abstract and concrete explorations. The blue converging area shows the focus on a (re)design for everyday life. Finally, the blocks indicate the steps of the process.

The entire process aims to design products/systems that incorporate values extracted from poems from different cultures. While developing on many cycles from abstract to concrete it also focuses on the (re)design of an everyday object or experience. This focus leads the process to a design that can be implemented in everyday life, as is highlighted with the blue converging area in Figure 3 . This focus is therefore a good bridge between abstract and concrete exploration.

A main motivation to design through the lens of poetic probes is to get sensitivity to the surrounding world in a subtle and unique way. At the most basic level, poems are important because they make us think, they open us up to wonder to the astonishing different ways to look at the world and express them in language.

Poems reveal areas of our own experience that we might have lost sight of or we might not have been ever aware of. On repeated reading, poems can disclose knowledge and insights. In its subtle yet powerful way of expression, poetic language can be seen 
as a discipline for re-engaging with a world we take too often for granted by putting feelings and emotions at the forefront.

\section{Methodological steps}

As shown in the model depicted in Figure 3, the design process develops in a number of steps, which are described below and exemplified by the students' projects.

\section{Experience (concrete)}

This phase aims to create sensitivity towards the non-literal qualities of the poem. Poems used as probing tools can be collected in different ways. For example, in the course "Poetry in Design", we invited the famous Dutch poet Jan Glas to kick off the course. He selected for us some of his own poems and recited them in Gronings or Plattdeutsch dialect. This was a lingua franca to all participants that allowed them to appreciate the sounds and rhythm of the poetic language beyond the understanding of the words. In this way the students could experience the active role of the reader/listener in making sense of the poem. Other poetic probes were selected and listened from Poetry International website, http://poetryinternationalweb.net/, a literary organisation that delivers quality poetry worldwide, often with videos of their recitation. Selection could be based on personal interest in a specific poet, language, culture or topic.

By listening, reciting, reading and discussing the poems, the deeper layers and hidden qualities were extracted.

The students of Teh Lampu show in their video their repetitive recitation exercises. Not only the translation (which was developed by themselves, see next step), but also the Indonesian version of the poem. The Indonesian language was foreign to all students, but they managed to find an Indonesian contact who recited it for them. This created sensitivity towards rhythm, flow and emotion of the poem. This step came back every time the students made a step forward in the design process moving from concrete to abstract exploration.

\section{Confrontation/Translate (toward abstract)}

In this step the students were asked to translate the poem (Poem 1 and 2). This could be from a foreign language to English or to their other native language. This step enhanced the sensitivity towards the poem and bridged towards the first extraction of qualities. Furthermore, this step allowed to capture and share personal experiences the students had with the poem.

The students of Teh Lampu project managed to capture qualities of the Indonesian language and culture by translating the poem with the support of an Indonesian contact. They compared the literal translation with a professional translation and learned that imagination played a more important role in the Indonesian language than in the English language. For example, Indonesian language translated into ' $\mathrm{He}$ feels to be in the middle of the jungle', whereas an English translation mentioned: 'It feels as if he is in the middle of the jungle', see Figure 4. 


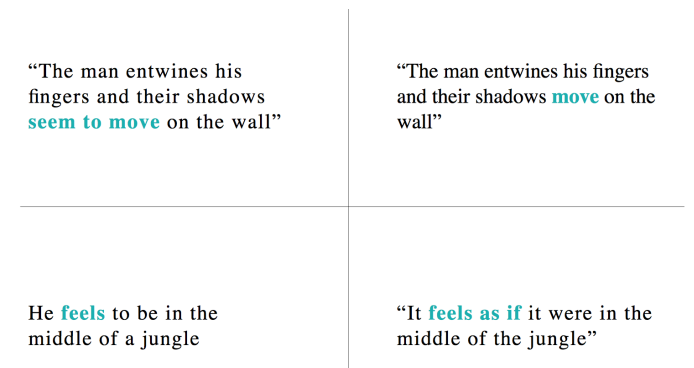

Fig. 4. Comparison of the Indonesian and English translation of "Bola Lampu".

Extract Qualities (abstract)

As a next step, the analysis of the poem was translated into qualities that embodied the non-rational and deeper layers of the poem.

To capture the qualities of their poem, the students working with the poem "Deer Enclosure" mapped every quality to a section of the poem. Furthermore, they provided an extensive description to every quality defining exactly what they meant. For example, the students extracted the quality 'secluded' from their translation 'pathless hills', see Figure 5 . They defined this quality by mentioning the hills do not have paths so not many people visit it.

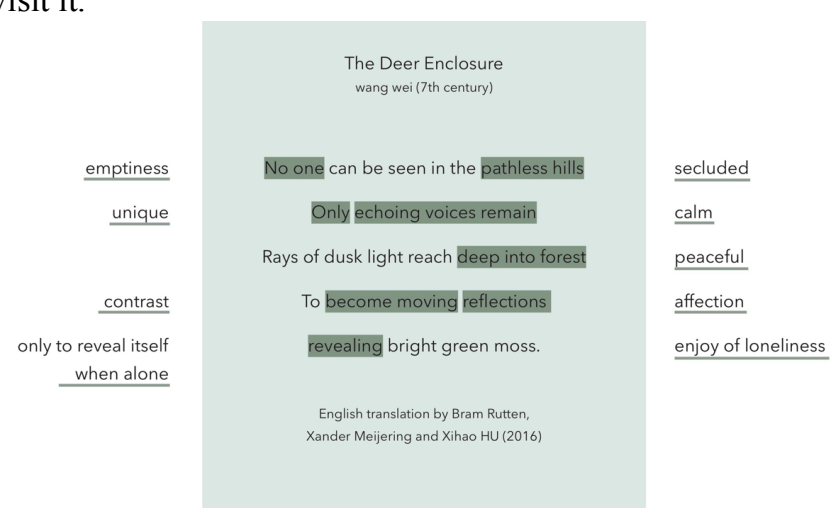

Fig. 5. Extract qualities of the poem: The Deer Enclosure.

Mood-board (concrete)

After having defined the qualities on a more abstract level, these are translated into a first concrete description of an experience. This is captured with a mood-board, which could have several forms, e.g. visual, drawings or video.

Both student groups used a video mood-board in which they explored material, context and human interaction qualities (Figure 6). Because of this activity, the understanding and definition of the qualities were also improved. Both video mood-boards can be found in the process videos of the student projects at https://vimeo.com/194223457 and https://vimeo.com/125128503.

Reflect on Qualities (abstract) 
After focusing on one experience the students broadened their perspectives again by exploring different materials, forms and interaction qualities that matched the extracted qualities and defined experience (Figure 6).

Different reflective qualities of materials were experimented with to find material properties that matched the qualities that were found in the poem. Sometimes more literal translations were made, for example the poem discussed a shadow play made by a light and hands. More abstract translations were explored as well with mirrors and graphical patterns.

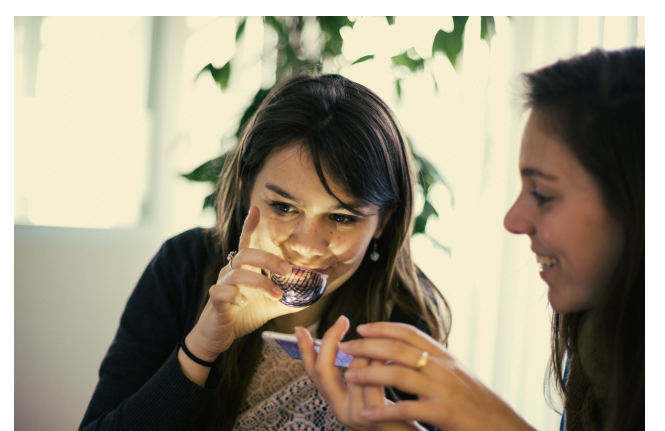

Fig. 6. Students exploring the qualities of different material and interaction properties for their 'Teh Lampu'.

\section{Prototype (concrete)}

The material explorations were combined with the extracted qualities and defined experience into first concepts and prototypes (Figure 7). The prototypes came closer to a focused redesign and allowed the students to actually experience the envisioned experience. By selecting existing products or experiences the implementation was done with subtle considerations instead of impacting changes of the design.

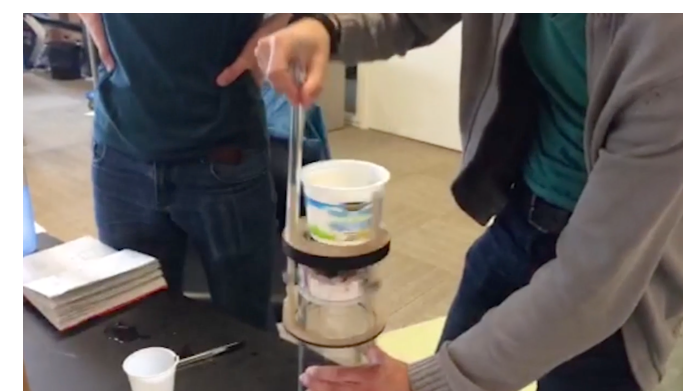

Fig. 7. Students testing a method to create the water vortex required for their design the 'Deer Enclosure'. 
The physical prototype allowed the students to experience the qualities of their design. Furthermore, other people, e.g. fellow students and lecturers could experience and reflect upon this experience as well. This helped the students to define to what extent the prototype matched the defined qualities and set experience.

The process of prototyping and reflection was iterative and was repeated as long as necessary to define a concept that meets the qualities and experiences of the poem.

Experiential Prototype (concrete)

The iterations on prototype development ended with a final experiential prototype, which according to the designers and people involved in the assessment, captured the experience narrated in the poem (Figure 8). The interaction with the prototypes was carefully designed to enrich the experience and to make it easier for the user to connect to the intended qualities.

The experiential prototype "Deer Enclosure" gives a good indication of this aesthetic qualities. The fluency of whirling around the water is an example of the attention paid to the interaction design of the answering machine: the way in which the user spins or pours the water affects the sound and the fluency of the spoken messages, and therefore the experience of the intended qualities of the design.

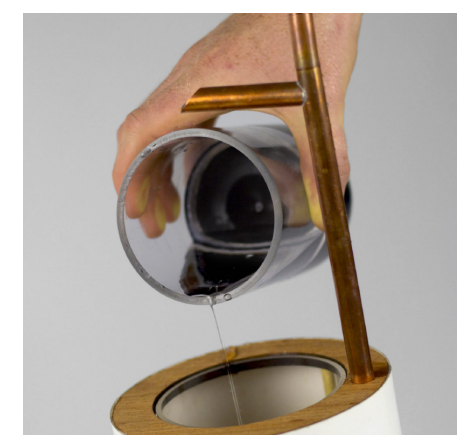

Fig. 8. The answering machine prototype inspired by 'Deer Enclosure'.

Capture \& Reflection (abstract)

The design process ended with capturing the design and its qualities and experience and reflecting together on the outcomes. This can be done in a written form but also pinpointing the properties of the design and its considerations.

\section{$5 \quad$ Reflections}

The design process ended with shared reflections about the approach and the obtained outcomes. In what follows we list the main insights that were reflected upon.

Overall the students reported that the process helped them to create more sensitivity towards cultural aspects. The process taught the students to design using a cultural probe, in this case a poem that was used to reflect on an experience and inspire a design. 
Students mentioned the defined steps as a good motivation to move onwards in the process. They valued the mood-board phase for example, as an opportunity to move the process from talking and discussing to doing and experiencing. Furthermore, the focus on an everyday object was valued by the students as a way to move from the abstract phase to concrete implementation.

By experiencing, translating and re-experiencing the poem the students realized how much qualities there could be found in one poem. Furthermore, they realised the many experiences one poem could embody. By designing with this insight, the artefact or design also obtained multi-interpretable qualities that supported subjective experiences.

\section{Conclusions}

In this paper we described an approach to UX Design that takes poems as cultural probes to inspire the design process. In doing this we explored the language of poetry as a means to focus on experiences from a cultural viewpoint. Central to this sensitivity is the language of poetry, a key means by which the uniqueness of the world is poetically brought about. In the language of poetry, the sound of the words, their flow and imagery are raised to an importance equal to that of their meaning, which remains open to the interpretation of the reader. The language of poetry also seeks to involve the reader in the text, placing importance on reader participation in the construction of meaning.

A poem aims to a subjective and personal experience, this is the reason why we used poems as cultural probes. In our design process, we constantly considered this by experiencing the poems by reading, listening and translating them. This allowed the designers to gain awareness on how a poem can be interpreted and experienced.

Our approach should be regarded as a way of encoding a design research practice to highlight subtleties and qualities that deserve to be manifested in a concrete design.

One can argue that anything can work as cultural probe in the design process. We believe that poems are a powerful and thought-provoking tool to address the subjective and personal experience. Practicing poems implies an open minded and focused attention to details of everyday experiences. Poetry is central to culture in its being capable of being a powerful lens through which looking at the inner experience and outer world.

\section{Acknowledgements}

The authors thank Gijs de Boer, Tove Elfferich, John Vlaming from the "Teh Lampu" project group and Xihao Hu, Bram Rutten and Xander Meijering, from "the Dear Enclosure" project group for their contributions. A special thanks to Jan Glas for his didactic poetry skills and to Ward van der Houwen co-lecturer of "Poetry in Design".

\section{References}


1. Law, E., Roto, V., Vermeeren, A., Kort, J., Hassenzahl, M.: Towards a shared definition of user experience (UX). Proceedings of CHI 5(10), (2008).

2. Roto, V., Law, E., Vermeeren, A., Hoonhout, J.: User Experience white paper - bringing clarity to the concept of user experience. All About UX, (2011).

3. Marti, P. Iacono, I. Experience over time: evaluating the experience of use of an interactive device on the short and medium term. International Journal on Multimedia Tools and Applications 76(4), 5095-5116 (2017).

4. Glanznig, M.: User experience research: modelling and describing the subjective. Interdisciplinary Description of Complex Systems 10(3), 235-247, (2012).

5. Hassenzahl, M.: Experience design: technology for all the right reasons. Morgan and Claypool Publishers, Essen (2010).

6. Wright, P., McCarthy, J.: Experience-centered design: designers, users, and communities in dialogue. Morgan and Claypool Publishers, (2010).

7. Norman, D. 2002. Emotion \& design: attractive things work better. Interactions 9(4), 3642 (2002).

8. Scheirer, J., Fernandez, R., Klein, Jonathan., Picard, R.: Frustrating the user on purpose: using biosignals in a pilot study to detect the user's emotional state. In: Cockton, G. (eds.) CHI 98 Conference Summary on Human Factors in Computing Systems (CHI'98). Special issue of Interacting with Computers, vol. 14, pp. 93-118. Elsevier, Amsterdam (1998).

9. Overbeeke, C., Djajadiningrat, J., Hummels, C., Wensveen, S.: Beauty in usability - forget about ease of use! In: Green, W., Jordan, P. (eds.) Pleasure with products : beyond usability, pp. 9-18. Taylor and Francis Ltd, London (2002).

10. Dunne, T., Raby, F.: Design Noir: The Secret Life of Electronic Products. 1st edn. Birkhäuser Verlag (2001).

11. Gaver, W.: What should we expect from research through design?. In: Proceedings of CHI'12, pp 937-946. ACM Press, New York (2012).

12. Graves Petersen, M., Iversen, O., Krogh, P., Ludvigsen, M.: Aesthetic interaction: a pragmatist's aesthetics of interactive systems. In: Proceedings of the 5th conference on Designing interactive systems: processes, practices, methods, and techniques (DIS'04), pp 269276. ACM, New York (2004).

13. Gaver, B., Dunne, T., Pacenti, E.: Design: cultural probes. Interactions 6(1), 21-29 (1999).

14. Crabtree, A., Hemmings, T., Roddon, T., Cheverst, K., Clarke, K., Dewsbury, G., Hughes, J., Rouncefield, M.: Designing with care : adapting cultural probes to inform design in sensitive settings. In: Proceedings of OzCHI, pp. 4-13. Ergonomics Society of Australia, Brisbane (2003).

15. Peeters, M., Megens, C., Hummels, C., Brombacher, A.: Experiential probes: probing for emerging behaviour patterns in everyday life. In: Proceedings of the 5th International Congress of International Association of Societies of Design Research, pp 26-30. IASDR, Tokio (2013).

16. Buchenau, M., Fulton-Suri, J.: Experience prototyping. In: Boyarski, D., Kellogg, W. (eds.) DIS 2000, pp. 424-433. ACM, New York (2000).

17. Mattelmäki, T., Battarbee, K.: Empathy Probes. In: Proceedings of the Participatory Design Conference, pp 266-271. PDC, Malmö (2002).

18. Mattelmäki, T.: Design probes. Helsinki: University of Art and Design, Helsinki (2006).

19. Marti, P. van der Houwen W., Poetry as a cross-cultural analysis and sensitizing tool in design. In: AI and Society: the Journal of Human-Centered System and Machine Intelligence, pp 1-14. Springer (2017). 